\title{
RECENT PROGRESS IN THE STANDARDIZATION OF DISINFECTANTS.*
}

BY

\section{JOHN MORRIS WEISS,}

Member of the Institute.

THE trend of medical science to-day is toward prevention rather than cure. The battle against those microscopic vegetable organisms which are the causative agents of disease is an increasing one. In this battle the true scientist uses, as one of his principal weapons, "disinfectants," or, to be more exact, "bactericides." The question as to the efficiency of these agents is one which cannot be solved by chemical analysis, but which requires methods, special in their field, to obtain a rational solution. It is the writer's intention to briefly give a résumé of the work which has been done in the past toward development of a standard bacteriological method for this purpose, as well as a general survey of the status of disinfectant standardization, both in this country and abroad.

The standardization of disinfectants as to their germicidal power is a matter of no little importance. At present there are many preparations on the market which are practically valueless, and whose use causes a menace of "fancied security" to the public. It is only just that the user of such an article knows exactly what its real efficiency is. This is the primal aim of disinfectant standardization--to protect the public from fraud, to give the layman an opportunity to exercise intelligent selection, to place upon the label of every article sold for germicidal purposes a plain, clear statement of its real value, instead of a multitude of fictitious claims and assertions, few of which could be substantiated by an impartial scientific inquiry.

The writer will pass over the various works published up to I88I. Before that time all experiments on the action of disinfectants had been qualitative. In the year mentioned, Koch ${ }^{1}$ put forth the "thread method" of testing the relative activity

* Communicated by the author.

Vol. CLXXV, No. 1050-4I 
of disinfectants. Threads impregnated with anthrax spores were submitted to the action of various dilutions of different disinfectants, thoroughly washed with sterile water to remove the residual disinfectant, and then planted on solid culture media. So far as the writer knows, this method is in no general use at present, having been supplanted by more improved procedures proposed later.

This method was used by various workers for some years, of whom Esmarch, ${ }^{2}$ Fraenkel, ${ }^{3}$ Henle, ${ }^{4}$ Behring, ${ }^{5}$ and Geppert ${ }^{6}$ may be mentioned. The next method set forward was by Krönig and Paul, ${ }^{7}$ and is known as the "garnet method." In this, garnets of a uniform size were sterilized and dipped into a culture of anthrax spores and allowed to dry. These were then placed in the disinfectant, and at various intervals several were removed, gently washed to remove excess of disinfectant, and then placed in a definite amount of sterile water and shaken strongly enough to detach the adherent organisms. A measured quantity of this wash water was then plated in the usual way, and the colonies of bacteria which developed were counted. In the same year Defries ${ }^{8}$ proposed a method which essentially consisted of placing a few drops of culture in a tube, allowing it to dry to a film, introducing the disinfectant, and, after the desired time had elapsed, pouring it out, washing, and adding sterile broth. Incubation then showed whether the bacteria had been killed. Neither of these methods is standard to-day, although the former has been quite extensively used by different workers, -Madsen and Nyman, ${ }^{9}$ Firth and Macfayden, ${ }^{10}$ etc.

The method that has enjoyed the greatest prominence and has come into most general use is the "drop method," as originally proposed by Rideal and Walker ${ }^{11}$ in 1903 .

The essential feature of this method is the comparison of the strength of disinfectants which kill B. typhosus in a definite time under carefully standardized conditions, with the strength of pure phenol solution necessary to accomplish the same results under the same conditions. Four dilutions of the disinfectant under test, and one dilution of phenol, are taken, and a definite amount of $B$. typhosus culture added to a definite amount of the various dilutions under sterile conditions. At various times, in regular order, sub-cultures are made, using a standardized loop, and the results observed after 48 hours' incubation. The quo- 
tient obtained by dividing the dilution of disinfectant which kills in a definite time by the dilution of phenol required to perform the same work in the same time is called the "Rideal-Walker coefficient" of the disinfectant. All the variables in the test have been carefully standardized, so that by close attention to details concordant results may be obtained by different workers.

This method was variously modified by the authors and others. Somerville and Walker ${ }^{12},{ }^{13},{ }^{14}$ proposed the use of organic matter in the diluent in the test. Their experiments concerned the use of I per cent. solution of blood-serum, mucin, peptone, casein, gelatin, blood and starch, and various mixtures of these materials. Chick and Martin ${ }^{15}$ suggested the addition of powdered feces in the test. Fowler ${ }^{16}$ proposed the use of urine in this work. Blyth ${ }^{17}$ used milk as added organic matter in the determination. All these suggestions were reviewed in great detail by Rideal and Orchard. ${ }^{18}$

The addition of organic matter was approved by them, but the kind and amount should be clearly stated in reporting the test. The organic matter used would naturally depend on the use to which the disinfectant was to be put, as suggested by Somerville and Walker.

In 1909 the Lancet Commission ${ }^{19}$ proposed several changes in the Rideal-Walker test. $B$. coli was used instead of $B$. typhosus, and MacConkey's bile-salt medium replaced beef broth. The time interval was lengthened, and spoons replaced the loops used for inoculation. For some years the literature of disinfectants was very much filled with controversy regarding the merits of the two methods. The final result was that the original Rideal-Walker method prevailed, and became the standard in England, while the method of the Lancet Commission fell into disuse.

Quite recently a similar controversy has been opened up again in this country. Anderson and McClintic ${ }^{20}$ propose what they style the "Hygienic Laboratory Method," to replace the Rideal-Walker method. The principal changes involved are the increase in the number of dilutions of both phenol and disinfectant, the change in strength of the nutrient broth, and the time factor used for comparison of postulant and phenol. Instead of using the 5-minute period, they employ an average of the $2^{\mathrm{I} / 2}-$ and 5 -minute periods. They have also introduced the doubtful 
expedient of unplugged seeding tubes, this being made necessary by the increasing number of dilutions used. This method has been adopted by the committee of the Laboratory Section of the American Public Health Association, ${ }^{21}$ but, aside from this, has not as yet found general acceptance.

More recently the Hygiene Section of the Eighth International Congress of Applied Chemistry appointed an international committee to confer with a committee of the Fifteenth International Congress of Hygiene and Dermography, to decide on a standard method for general international use, but as yet no report is forthcoming.

Walker and Weiss ${ }^{22}$ have investigated the purity of the phenol control, and have given a new method to insure this, based on the solidifying point of the phenol used as a standard, which should not be below $40^{\circ} \mathrm{C}$.

This is the general historical review of the subject, and the writer would now consider the extent to which standardization of disinfectants has been made official, and the logical effect of such official recognition.

Abroad, disinfectant standardization has reached its highest development in England and her colonies. In Germany, France, and other European countries, so far as the writer has been able to learn, there is no official method for standardization and comparison. Doubtless it is carried on, and various methods are used, but the subject on the Continent does not seem to have received the attention it deserves.

This reminds the writer somewhat of a passage in "Innocents Abroad," by the late Samuel Clemens (Mark Twain). He and his party are landing at a certain port, and before being allowed to enter are fumigated. In speaking of it, he says:

"These miserable outcasts called that fumigating us, and the term was a tame one indeed. They fumigated us to guard themselves against the cholera, though we hailed from no infected port. . . . However, they must keep epidemics away somehow or other, and fumigation is cheaper than soap. They must either wash themselves or fumigate other people. Some of the lower classes had rather die than wash, but the fumigation of strangers causes them no pangs."

That is the way many of us feel about disinfection in general: we know it is a good thing, but like the bother and trouble 
applied to the "other fellow" rather than to ourselves. However, seriously speaking, it is most probable that the more enlightened continental countries, which are under a more or less bureaucratic or autocratic government, can regulate the standard of efficiency of disinfectants to the necessary degree without the measures of popular education necessary in the more individualistic society of countries like England and the United States.

In England the Rideal-Walker test is the universal official standard. Among the British authorities using the RidealWalker test to control supplies of disinfectants are the War Office, the Admiralty, the Board of Trade, the India Office, the Office of Works, the Metropolitan Asylums Board, and the cities of London, Westminster, Birmingham, Manchester, Nottingham, Edinburgh, etc. This takes no account of private industrial and semi-public concerns, such as laundries and hospitals, which demand that disinfectants, in common with other purchased supplies, undergo a test to show their actual value for the purposes for which they are intended. The public, too, is educated to the point of knowing what disinfection really means, and the charlatan, imitation articles, which rely on an odor as their recommendation, are mostly reserved for the export trade.

Among the English colonial governments using the RidealWalker test as a control may be mentioned Cape Colony, Natal, Western Australia, Victoria, Queensland, Madras, Bombay, Mysore, Shanghai, Hong Kong, etc. Many of the colonial railways also use this method of control in purchases of disinfectant supplies. The Federation of South African States put into effect a very novel and original law. All shipments of disinfectants entering the custom house are subjected to a Rideal-Walker test, and all under 5 have to pay a considerable duty ( I 5 per cent.), while those higher than the figure given come in free. The effect of this law is very well brought out in the following extract from the report of the medical officer of health for Cape Colony for the year 1907:

"Samples of disinfectants submitted by agents tendering for contracts to supply Government departments, as well as samples from all consignments of unknown brands of disinfectants passing through the custom, continue to be examined by the RidealWalker test in the Public Health Laboratory.

"No table of the various coefficients obtained during the year 
is attached to this report, as it was found that some firms were using the published results for the purposes of advertisement.

"The majority of the higher-grade disinfectants have shown a marked rise in the Rideal-Walker coefficient, and from the samples received from the Controller of Customs it would appear that this colony is no longer being made the dumpingground for worthless, so-called disinfectants, whose only resemblance to germicides consisted in their possessing a strong smell of coal tar, and being able to produce an opaque emulsion when added to water."

This extract shows most clearly that standardization of disinfectants militates against the dishonest manufacturer, to the benefit of the public, and proves that the subject is one well worth serious consideration in this country.

In the United States to-day great interest has been manifested in the question, but so far but one State has taken official cognizance of the subject. This State is Maryland, and the recognition occurs in Regulation No. 2, Labelling of Disinfectants,-State Board of Health, Maryland, revised to May I, I9II. The portion of interest in this connection reads as follows :

"All disinfectants manufactured or sold in this State must bear a label showing the carbolic acid coefficient or relative germicidal strength of such disinfectants, as compared with pure carbolic acid.

"In determining the relative germicidal value of disinfectants, the application of the Rideal-Walker test to the typhoid bacillus in a 24-hour bouillon culture may be made, and such results will be accepted until further notice.

"The statement of the coefficient should be made as follows:

"Carbolic acid coefficient 0.3 , or I.2, etc., etc.

"This statement may appear on the principal label, or on a supplemental label or sticker."

In the opinion of the writer, every State should have such a law. It should go even further. There should be a national decree compelling the bactericidal efficiency of the articles to be placed upon each package. This would be along the lines of the present Food and Drug Act, or that relating to insecticides and fungicides. Inefficient disinfection is worse than no disinfection at all, and the user should have some real guarantee that the 
material he uses is capable of accomplishing the work for which it is designed. In the present state of chemical and bacteriological science there is no excuse for this not being brought about.

Antecedent to proper legal measures, it is necessary that a standardized method be adopted by unbiased authorities for use in the various laboratories throughout the country, in order that the method of determination may be incorporated in the various acts and ordinances covering this subject. This is necessary in order to prevent useless confusion and litigation, with consequential unfair evasions by unscrupulous manufacturers and dealers.

To the writer's mind, the method to be selected should have the following features:

r. Well-defined technique.

2. Uniformity of results.

3. Simplicity.

4. Adaptability.

By well-defined technique is meant that all details of the test be clearly set forth and standardized to such an extent that no latitude is allowed the worker, either in the manipulation of the test or in the interpretation of the results. The writer has had considerable experience in standardizing various tests used in the coal-tar industry in this country. These tests are largely physical in their nature, such as distillation work, extraction work, specific gravities, so-called melting point or fusing point of bitumens, etc. The actual figures obtained in these tests are not as important as their comparative character-a means by which buyer and seller can agree upon specifications for products which are of more or less unknown composition, and which consist of a complex mixture of organic compounds. Here it is very necessary that the methods be such that the ordinary workers can obtain concordant results. It is surprising how slight details can cause marked variations in these proximate analyses, and how factors which would not ordinarily be given more than passing notice cause wide deviations between different operators. Only by working out all small details, and determining the effect of each minute factor, is it possible to know just which points demand careful attention, and which may be regarded as negligible influences. Any bacteriological test for the purposes which this 
paper discusses must also pass through such a stage of minute investigation, and emerge, fortified at all points against the differing ideas of various workers as to the essential and the negligible features.

The second requirement, of uniformity of results, is a logical sequel to the first. The only further requisite to this end is that the various workers be so well informed of the necessary details of the test that there is no excuse for deviation or error. If such occur it may be directly chargeable to wilful ignorance on the part of one or the other of the workers.

The third account, "simplicity," is also one of prime importance. If possible, the test should be susceptible of being carried out in the ordinary laboratory, with as little inconvenience and additional apparatus as possible, other than the ordinary bacteriological appliances. It should not be a long, tedious operation, or one requiring specialized training. This is necessary if control is to be constant; in other words, we want accomplishment of results with the minimum effort compatible with accurate and serviceable work. Then, too, if the test is not too long and tedious, there is a greater chance of the worker paying strict and careful attention to those details which are so essential to uniformity.

The fourth and last requirement, "adaptability," is designed to enable the knowledge of disinfectant action to be obtained under special conditions which correspond to the conditions under which the disinfectant is to be used. For ordinary general purposes it would be sufficient to know the coefficient of a disinfectant per se,-that is, in presence of bacteria alone, without the addition of organic matter. However, a throat specialist desires to know the disinfecting action in the presence of mucus, the surgeon the action in the presence of blood; the army surgeon, in caring for drainage, must know the value in the presence of feces, urine, etc. Accordingly, in these special cases, mucin, serum, urea, etc., should be added in order to determine their effect. The test should be such that the addition of various materials could be made in the diluent without otherwise changing the technique or introducing needless complications.

Such a method adopted, legislation should follow. Opposition to such legal action could only come from those whose interests were threatened, and this would naturally be those who were 
selling inefficient disinfectants under false pretences. To-day I believe the public conscience has so developed that such opposition would be given little consideration, once the general public is awakened to the importance of the subject.

As mentioned before, the situation in this country is in the controversial state. The merits of the Rideal-Walker method, and the Hygienic Laboratory method, as proposed by Anderson and McClintic, are undergoing considerable discussion, and the writer feels that it would not be amiss to give here his own opinions and conclusions.

It is far easier to obtain concordant results with the RidealWalker method than with the modified method of Anderson and McClintic, and the reason for this is clearly brought out when the count of simplicity is considered.

The writer has had experience with the operation of both methods, and feels that there could be no unbiased critic but would concede at the start that the Hygienic Laboratory method is far more cumbrous, complicated, and involved than is the older method. It may be noticed in the report of the Committee of the Public Health Association (loc. cit.) that the inference is made that there were still some considerable discrepancies observed in tests of duplicate samples by different members of the committee. Further work was suggested to determine the cause of the discrepancies. Now, if the members of this committee, who should, supposedly, be the workers par excellence in carrying out the method, fail to obtain consistent concordant results, what chance has the "outsider"? It would seem poor policy to indorse a method as a standard, when operators of this high degree of excellence could not consistently check each other's work. The writer feels that this failure is due, in part at least, to the cumbrousness of the Hygienic Laboratory test. English experience has shown that workers not specially trained can obtain concordant figures with the Rideal-Walker method.

In carrying out the Rideal-Walker tests there are but five dilutions in all, which means an inoculation only every half minute. This gives ample time for sterilization of the needle, removal of the cotton plugs from the seeding and medication tubes, making the plant, replacing the plugs, setting the tubes back in their places, and taking up a new pair. In the Hygienic Laboratory method, on the other hand, from io to is dilutions 
of phenol and postulant are used, thereby allowing but Io to ${ }_{5}$ seconds for all these operations. As this would be physically impossible, open, broad seeding tubes are used, and during the test these are exposed to organisms from the air for a period of I $71 / 2$ minutes, at the very least, and usually considerably more. Any bacteriologist knows that under such conditions some contamination is not a chance, but a certainty, unless a special sterile, dust-proof room is provided, and even then the difficulties would be very large.

In the Rideal-Walker method, on the other hand, all tubes are sealed with sterile cotton plugs, except at the actual moment of inoculation or sub-culture, and the danger of contamination is reduced to a minimum.

Even with the open seeding tubes, and only io dilutions to handle, the Hygienic Laboratory method requires considerable mechanical practice before the operator can begin to perform all the operations and still accurately preserve the time intervals. This is probably one of the principal reasons for discordance in results by this method, and one which cannot be eliminated so long as open seeding tubes are used.

So far as adaptability is concerned, the two methods are equal as regards the introduction of organic matter in the diluent. for this addition occasions no change in their regular technique.

The simplicity of the Rideal-Walker method should, in the writer's opinion, give it the preference over the later proposal of the Hygienic Laboratory, because this simplicity makes it more universally applicable. With it many more consumers would be able to test their disinfectant supplies in their own laboratories. It would be far more to the interest of the general public if the means of ascertaining the truth were more accessible and easy of attainment.

But whichever method prevails, the writer will feel that real progress has been made, and, after all, the end in this case is of far greater importance than the means. Progress will be slower in one case than in the other, but the adoption of some test is imperative.

Much is to be hoped from the committee recently appointed by the Eighth International Congress of Applied Chemistry, which will co-operate with the committees of the Fifteenth International Congress on Hygiene and Dermography. Unfortun- 
ately, this joint committee is not required to report for three or four years, - that is, before the next Congress. The writer hopes that, so far as this country is concerned, this much-needed reform will not be delayed so long. Let us hope that a method, acceptable to all workers in this country, will be chosen for use as a control over the bactericidal efficiency of various preparations and compounds offered for purposes of disinfection.

This accomplished, it will be the duty of true scientific men to spare no effort and waste no opportunity to demonstrate to the public at large the need and use of this subject. If the public is once awakened in this country, legislation will surely follow, and we will compel honesty and real merit in all disinfectants, a subject for a long time a mystery to the layman and to the average physician and health officer, which has been accepted rather on faith than upon knowledge.

It will be an incalculable gain for preventive medical science, for sanitation, and for the health of the public at large. It will do its share toward elimination of disease and suffering, and serve to shield the careful individuals from the ignorant carelessness of others.

\section{REFERENCES.}

${ }^{1}$ Koch: Mittheilungen a. d. Kais. Gesundheitamte, vol. i, p. 234.

${ }^{2}$ Esmarch: Centralblatt für Bakt., vol. i, part 2, p. 295.

${ }^{3}$ Fraenkel: Zeit. f. Hygiene, vol. vi.

${ }^{4}$ Henle: Archiv f. Hygiene, vol. vi.

${ }^{5}$ Behring: Zeit. f. Hygiene, vol. vi, 1889 .

${ }^{6}$ Geppert: Deutsche med. Wochenschrift, r889, p. 789 .

'Kronig and Paul: Zeit. f. Hygiene, vol. xxv.

${ }^{8}$ Defries: Journ. San Inst., vol. xvii, p. $4 \mathrm{I} 6$.

${ }^{\circ}$ Madsen and Nyman: Zeit. f. Hygiene, vol, 1vii.

${ }^{10}$ Firth and Macfayden: Journ. Roy. San. Inst, vol, xxvii.

${ }^{11}$ Rideal and Walker: Journ. Roy. San. Inst., vol. xxiv, p. 424.

${ }^{13}$ Somerville and Walker: San. Record, Nov. 29, I906.

${ }^{13}$ Somerville and Walker: San. Record, May 9, 1907.

${ }^{14}$ Somerville and Walker: San. Record, Mar. 26, 1908.

${ }^{15}$ Chick and Martin: Journ. Hygiene, vol. viii, p. 665.

${ }^{16}$ Fowler: Royal Army Med. Journ., vol. vi, p. 6.

${ }^{17}$ Blythe: Journ. Soc. Chem. Ind., vol, xxv, p. II 84 .

${ }^{18}$ Rideal and Orchard: The Medical Officer, June 26, 1909.

${ }^{19}$ Lancet, 1909, pp. I454, I516, I612.

${ }^{20}$ Anderson and McClintic: Journ. Infect. Dis., vol. viii, p. I.

2. Amer. Journ. Public Health, October, I9I2.

${ }^{22}$ Walker and Weiss: Journai of The Franklin Institute, July, Igiz. 